\title{
JNVESTJGAACJÓN
}

\section{Lipid components and oxidative status of selected specialty oils}

\author{
By S.R.P. Madawala ${ }^{a \star}$, S.P. Kochhar ${ }^{b}$ and P.C. Dutta ${ }^{a}$
}

aDepartment of Food Science, Division of Food Chemistry, Swedish University of Agricultural Sciences, SLU, Uppsala BioCenter, Box 7051, SE-75007, Uppsala, Sweden

${ }^{b}$ SPK Consultancy Services, 14 Holmemoor Drive, Sonning, Reading RG4 6TE, UK.

${ }^{*}$ Corresponding author: samanthi.madawala@slu.se

\section{RESUMEN}

Componentes lipídicos y estado oxidativo de una selección de aceites especiales.

Muchos aceites vegetales se venden como aceites especiales debido a su flavor, gusto y características distintas. Muestras de aceites especiales de almendra, avellana, nuez, nuez de macadamia, argán, aguacate, semillas de uva, de sésamo tostadas, salvado de arroz, y aceites orgánico de semillas de colza prensado en frío y, prensado caliente, y refinados que se producen y comercializan al por menor, se obtuvieron en comercios de grandes superficies en Reading, Reino Unido, y Uppsala, Suecia, y se les determinó su composición detallada de lípidos y su estado oxidativo. Los niveles de peróxidos (PV) fueron bastante bajos (0,5 a 1,3 mEq $\mathrm{O}_{2} / \mathrm{kg}$ ), pero la acidez (AV) y los valores de la estabilidad oxidativa Rancimat a $100^{\circ} \mathrm{C}$ (excepto los aceites de colza) variaron considerablemente $(0,5-15,5 \%)$ y $(4,2$ a $37,0 \mathrm{~h})$, respectivamente. El aceite de nuez de macadamia se encontró que fue el aceite más estable, seguido por el aceite de argán, mientras que el aceite de nuez fue el menos estable. Entre los aceites especiales, el aceite de nuez de macadamia, presentó el menor nivel de ácidos grasos poliinsaturados (AGPI) (4\%) y aceite de nuez el más alto $(71 \%)$. El aceite ecológico de colza prensado en frío tenía un contenido considerablemente menor de AGPI (27\%) en comparación con otros aceites de colza (28-35\%). En todas las muestras, $\alpha-y \gamma$ - fueron los principales tocoferoles, y el aceite de nuez presentó los niveles más bajos. Los esteroles totales variaron desde 889 hasta $15.106 \mathrm{mg} / \mathrm{g}$ de aceite. Los principales esteroles fueron: $\beta$-sitosterol (61-85\%) y el campesterol (6-20\%). El aceite de argán contenía schottenol (35\%) y espinasterol (32\%). En comparación con los valores de la literatura, no se observaron diferencias significativas entre los aceites de colza procesados de manera diferente, cultivado ecológicamente y prensado en frío y otros aceites especiales de este estudio.

PALABRAS CLAVE: Aceite de colza ecológico - Aceites de colza de diferentes procesados - Aceites de nuez - Aceites especiales - Estado oxidativo - Lípidos - Rancimat.

\section{SUMMARY}

Lipid components and oxidative status of selected specialty oils.

Many vegetable oils are marketed as specialty oils because of their retained flavors, tastes and distinct characteristics. Specialty oil samples which were commercially produced and retailed were purchased from local superstores in Reading, UK, and Uppsala, Sweden and profiled for detailed lipid composition and oxidative status. These oil samples include: almond, hazelnut, walnut, macadamia nut, argan, avocado, grape seed, roasted sesame, rice bran, cold pressed, organic and cold pressed, warm pressed and refined rapeseed oils. The levels of PV were quite low $0.5-1.3 \mathrm{mEq}$ $\mathrm{O}_{2} / \mathrm{kg}$ ) but $\mathrm{AV}$ and Rancimat values at $100^{\circ} \mathrm{C}$ (except for rapeseed oils) varied considerably at (0.5-15.5) and (4.2-37.0 h) respectively. Macadamia nut oil was found to be the most stable oil followed by argan oil, while walnut oil was the least stable. Among the specialty oils, macadamia nut oil had the lowest $(4 \%)$ and walnut oil had the highest $(71 \%)$ level of total PUFA. The organic cold pressed rapeseed oil had considerably lower PUFA (27\%) compared with other rapeseed oils (28$35 \%$ ). In all the samples, $\alpha$ - and $\gamma$ - tocopherols were the major tocopherols; nut oils had generally lower levels. Total sterols ranged from 889 to $15,106 \mu \mathrm{g} / \mathrm{g}$ oil. The major sterols were $\beta$-sitosterol (61-85\%) and campesterol (6-20\%). Argan oil contained schottenol (35\%) and spinasterol (32\%). Compared with literature values, no marked differences were observed among the differently processed, organically grown or cold pressed rapeseed oils and other specialty oils in this study.

KEY-WORDS: Differently processed rapeseed oils Organic rapeseed oil - Lipids - Nut oils - Oxidative status - Rancimat - Specialty oils.

\section{INTRODUCTION}

Among edible fats and oils, a considerable number of products are sold as specialty oils which have undergone minimum or no processing. Examples of such products, commonly known as specialty oils, include extra virgin olive oils, oils extracted from different nuts, cold pressed rapeseed oils, etc. Many specialty oils are unique in flavor, odor and special characteristics which suggest their specific use for cosmetic, therapeutic and dietary purposes. Rapeseed oil represents the most common vegetable oil consumed in Sweden along with other Nordic countries. Among the different commercially available rapeseed oils, cold pressed oils generally claim higher quality. They are extracted without applying heat and promoted as specialty oils, sold at a higher price. The cold 
pressed oil products may contain both pro- and antioxidative compounds and that would affect the quality of these oils (Pekkarinen et al., 1998).

The general perception of consumers is that foods grown organically and subjected to less processing are better and healthier and thus cold pressed oil is an appealing choice since no solvents and no further processing other than filtering are involved (Koski et al., 2002). Studies reveal that organic crops tend to contain higher dry matter, certain minerals, antioxidants (phenols, resveratrol) and lower amounts of nitrates, residues of toxic chemical pesticides, fungicides and herbicides compared with conventionally grown crops (Lairon, 2010). In order to comply with these trends and environmental concerns, the edible fats and oils industries are also developing milder processing conditions (Jung et al., 2009).

Extensive studies have shown that plant sterols and stanols reduce total- and LDL- cholesterol levels in humans (Normen et al., 2004). Through a study with home prepared foods in real-life conditions, it has been found that part of the beneficial effects of the enhanced Mediterranean diet on the lipid profile is due to an increased consumption of phytosterols and other constituents which might be bioactive even in small amounts in their natural food matrix (Escurriol et al., 2009). Natural oils are also preferred due to higher levels of other bioactive components such as squalene, tocopherols and tocotrienols compared with their processed counterparts. Beyond the active role of $\alpha$-tocopherol, it has been found that $\gamma$-and $\delta$-tocopherols and tocotrienols have a specific pharmaco dynamic profile due to their different metabolic patterns (Franke et al., 2007). For studying the overall quality of oil, the parameters such as detailed fatty acid composition, content and composition of unsaponifiables (sterols, tocopherols, etc.) and oxidative status and stability are generally assessed. The stability of oil is important for nutritional and functional quality as well as for its organoleptic properties.

Studies on the effects of minor oil components on oxidative status for differently processed rapeseed oils are scarce (Pekkarinen et al., 1998, Koski et al., 2002). To our knowledge, no published data on minor lipid components is available for commercially available, organically grown, cold pressed rapeseed oil. The main objective of this study was to evaluate the oxidative status and stability of selected specialty oils commercially available in the UK, commercial samples of differently processed rapeseed oils, and organic and cold pressed rapeseed oils collected in Sweden in relation to their fatty acid profiles and minor antioxidant components.

\section{MATERIALS AND METHODS}

\subsection{Materials}

Five different cold pressed, one ecological and cold pressed, one warm pressed and one fully refined commercial rapeseed oil were purchased from a retail market in Uppsala, Sweden. They are marketed under the following brand names and producers:. extra fine cold pressed rapeseed oil (cold-pressed 1), Arvid Nordquist, Solna, Sweden; Swedish cold pressed rapeseed oil (cold pressed 2), ICA AB, Solna, Sweden; cold pressed extra virgin rapeseed oil (cold pressed 3), Druvan, Eslöv, Sweden; ZETA (Fyllig \& Nötig) Swedish cold pressed rapeseed oil (cold pressed 4), Luca \& Di Luca AB, Stockholm, Sweden; ZETA (mild \& blommig) Swedish cold pressed rapeseed oil (cold pressed 5), Luca \& Di Luca AB, Stockholm, Sweden; ICA Rapeseed oil (fully refined), ICA Handlarnas AB, Solna, Sweden; ICA organic Swedish cold pressed rapeseed oil (organic), Ektek Oil AB, Järfälla, Sweden; warm pressed rapeseed oil (warm pressed), Druvan, Eslöv, Sweden. Specialty oil samples of almond, hazelnut, walnut, macadamia nut, argan, avocado, grape seed, roasted sesame and rice bran oils were purchased from local retail superstores in Reading, UK, and were provided by SPK Consultancy Services, Reading, UK.

\subsection{Determination of peroxide value (PV)}

Approximately $0.02 \mathrm{~g}$ of lipid sample in triplicate were used to analyze PV following the IDF standard method 7A (1991).

\subsection{Determination of $p$-anisidine value (AV)}

AV was determined using $2.5 \mathrm{~g}$ oil in triplicate according to the published method of the IUPAC (1987).

\subsection{Determination of oxidation stability by Rancimat}

The Oxidation stability of the oils was measured using $2.5 \mathrm{~g}$ oil sample in duplicate as described previously by Savage et al. (1997), except that accelerated oxidation was performed at $100^{\circ} \mathrm{C}$ and 20L/h air flow rate using a Rancimat 679 (Metrohm, Herisau, Switzerland).

\subsection{Analysis of fatty acid methyl esters (FAME)}

Preparation of FAME was done using $10 \mathrm{mg}$ oil samples and analyzed by capillary column GC according to the published method (AzadmardDamirchi and Dutta, 2008).

\subsection{Analysis of tocopherols and tocotrienols}

Tocopherols and tocotrienols were analyed by direct injection of the oil samples dissolved in HPLC grade heptane (ca.10mg/ml) using an HPLC coupled to a fluorescence detector according to the method published previously (Azadmard-Damirchiand Dutta, 2008). 


\subsection{Analysis of sterols by GC and GC-MS}

The Trimethylsilylether derivatives of sterols after saponification of the oil samples (ca. $20 \mathrm{mg}$ ) were determined by capillary column GC using $5 \alpha$-cholestane as internal standard according to the published method (Azadmard-Damirchi and Dutta, 2008). Confirmation of the sterol structures was made with GC-MS using a GC 8000 Top Series GC and an AS800 auto sampler (CE Instruments, Thermo Quest Italia S.P.A., MI, Italy) coupled to a Voyager mass spectrometer with Xcalibur version 1.2 (Finnigan, Thermo Quest, Manchester, UK). The column and conditions used were the same as for the GC.

\section{RESULTS AND DISCUSSION}

\subsection{Fatty acid composition}

The fatty acid profile of the different specialty oils is presented in Table 1. The high polyunsaturated fatty acid (PUFA) contents (71 and $69 \%$ respectively) observed in walnut and grape seed oil explained the low oxidative stability of these oils. Oleic acid (18:1) was the predominant fatty acid in all the oils except for the walnut and grape seed oils in which linoleic acid (18:2) was observed at higher levels. Walnut oil had a significantly high amount of linolenic acid (18:3) which was $10.4 \%$ compared with $0.3 \%$ in grape seed oil. Macadamia nut, hazelnut, avocado, almond and rapeseed oils showed the highest levels of monounsaturated fatty acids (MUFA). Macadamia nut oil contained $18 \%$ palmitoleic acid (16:1) which was not common in many specialty oils. According to the published literature (Charrouf and Guillaume, 2008; Crews et al., 2005, 2005, 2006; Dubois et al., 2007; Kochhar, 2002; Lu et al., 2009; Maguire et al., 2004; Rubio et al., 2009; Savage et al., 1997, 1999), in all the oils tested, SFA (saturated fatty acid) levels were comparatively low except for rice bran and argan oil. Among differently processed rapeseed oils, the level of SFA was very similar $6-7 \%$. MUFA varied from $59-66 \%$ with oleic acid being the dominant one. The PUFA contents in these samples varied from $28-35 \%$ and linoleic acid was observed as the dominant fatty acid (18-22\%), and the linolenic acid content varied from $8-12 \%$. Organic cold pressed rapeseed oil had a bit higher level at $18: 1(62 \%)$ compared with the other rapeseed oils $(54-61 \%)$. This higher level of oleic acid was compensated by the lower levels of $18: 2(18 \%)$ and $18: 3(8 \%)$. The ranges of these fatty acids in the other rapeseed oil samples were $(18-22 \%)$ and (8$12 \%)$, respectively. All the rapeseed oil samples had relatively higher levels of vaccenic acid (3-4\%) compared with other specialty oils, as shown in Table 1 . The fatty acid profiles observed for different brands of rapeseed oils were generally uniform and concur with the published data (Dubois et al., 2007; Koski et al., 2002). No data is known to our knowledge on fatty acids in organic rapeseed oil, however, a previous study has shown that the level of oleic acid was higher in organic virgin olive oil (Gutiérrez et al., 1999). We did not make any effort to identify trans fatty acids in the samples. If there were any trans fatty acids present in some samples those are presented under the column "Others" in Table 1. It has been reported that minor amounts of trans fatty acids are present in commercially refined edible oils. The authors have cautioned that deodorization temperature is critical to minimize the formation of trans fatty acids in oils containing high amounts of polyunsaturated fatty acids (Tasan et al., 2011).

\subsection{Tocopherol (Tp) and tocotrienol $\left(\mathrm{Tt}_{3}\right)$ content}

The contents of different isomers of tocopherol $(\mathrm{Tp})$ and tocotrienol $\left(\mathrm{Tt}_{3}\right)$ in the different specialty oil samples showed wide variations (Table 2). $\alpha$-Tp and $\gamma$-Tp were the main isomers present in all the specialty oil samples. In almond, hazelnut, avocado and grape seed oils, the predominant isomer was $\alpha$-Tp, while $\gamma$-Tp was predominant in all the other samples. Among the different tree nut oils, macadamia nut oil showed the lowest $\mathrm{Tp}$ and $\mathrm{Tt}_{3}$ and the total tocopherol level was only $54 \mu \mathrm{g} / \mathrm{g}$ oil. This was comparable with the data published by Kaijser et al. (2000).

In accordance with the data published by Crews et al. (2006), only $\gamma$-Tp could be detected in roasted sesame oil. According to Kochhar (2002), the Tp in crude sesame oils can vary from $400-700 \mu \mathrm{g} / \mathrm{g}$ of which $\gamma$-Tp is predominant along with a small proportion of $\delta$-Tp. The roasting of sesame seeds improves the oxidation stability of its oil and thereby protects antioxidant compounds like tocopherols in the oil.

The highest $\mathrm{Tt}_{3}$ levels were observed in rice bran and grape seed oil. The different levels of different Tp observed in argan oil were well in accordance with the data published previously by Khallouki et al. (2003). The relatively high stability of rice bran oil is most likely due to the combined effect of oryzanol, phytosterols, squalene, tocopherols and tocotrienols, while the stability of roasted sesame oil is due to the higher antioxidant activity of the sesamol formed from sesamolin during roasting and the high level of potent $\gamma$-tocopherol antioxidants (Kochhar, 2002).

Among the specialty samples investigated, hazelnut oil and macadamia nut oil contained $\alpha-\mathrm{Tt}_{3}$, whereas ricebran oil and roasted sesame oils contained high amounts of both $\alpha-\mathrm{Tt}_{3}$ and $\gamma-\mathrm{Tt}_{3}$ (Table 2). The literature values concerning total tocopherols in sesame oils vary widely ranging from $88-1609 \mu \mathrm{g} / \mathrm{g}$ oil (Kochhar, 2002). The total tocol content in ricebran oil in our study $(567 \mu \mathrm{g} / \mathrm{g})$ is in good agreement with this data and Abidi (2003). In walnut oil, $\gamma$ - and $\delta$-Tp contents were in accordance with the data published by Crews et al. (2005) except for $\alpha$-Tp. The predominant isomer $\gamma$-Tp represents $69 \%$ of the total tocol contents (373 $\mu \mathrm{g} / \mathrm{g}$ ) which is a similar finding to published data (Crews et al., 2005; Miraliakbari and Shahidi, 2008). 





Table 2

Content of tocopherols (Tp) and tocotrienols $\left(\mathrm{Tt}_{3}\right)(\mu \mathrm{g} / \mathrm{g}$ oil) in different specialty oils

\begin{tabular}{|c|c|c|c|c|c|c|c|}
\hline Sample & $\alpha-T p \pm$ SD & $\alpha-\mathrm{Tt}_{3} \pm \mathrm{SD}$ & $\beta-T p \pm$ SD & $\gamma-T p \pm$ SD & $\gamma-\mathrm{Tp}_{3} \pm \mathrm{SD}$ & $\delta-\mathrm{Tp} \pm \mathrm{SD}$ & Total \pm SD \\
\hline Almond oil & $174 \pm 5$ & nd & $16 \pm 6$ & $57 \pm 6$ & $\operatorname{tr}$ & $17 \pm 4$ & $264 \pm 21$ \\
\hline Hazelnut oil & $87 \pm 3$ & $28 \pm 2$ & nd & nd & nd & nd & $115 \pm 5$ \\
\hline Walnut oil & $71 \pm 2$ & nd & nd & $259 \pm 19$ & nd & $43 \pm 2$ & $373 \pm 12$ \\
\hline Mac. nut oil & $8 \pm 0$ & $20 \pm 1$ & nd & $15 \pm 0$ & $\operatorname{tr}$ & $11 \pm 1$ & $54 \pm 2$ \\
\hline Argan oil & $90 \pm 3$ & nd & nd & $463 \pm 20$ & nd & $71 \pm 6$ & $624 \pm 29$ \\
\hline Avocado oil & $89 \pm 2$ & nd & $8 \pm 1$ & $38 \pm 2$ & nd & $14 \pm 3$ & $149 \pm 8$ \\
\hline Grapeseed oil & $216 \pm 3$ & $137 \pm 5$ & nd & $111 \pm 8$ & $191 \pm 9$ & nd & $655 \pm 25$ \\
\hline Sesame oil, roasted & $251 \pm 8$ & nd & nd & $521 \pm 22$ & nd & nd & $772 \pm 30$ \\
\hline Ricebran oil & $108 \pm 2$ & $63 \pm 3$ & nd & $112 \pm 3$ & $284 \pm 13$ & nd & $567 \pm 21$ \\
\hline $\begin{array}{l}\text { Rapeseed oil, } \\
\text { cold-pressed } 1\end{array}$ & $211 \pm 6$ & nd & nd & $396 \pm 10$ & nd & $\operatorname{tr}$ & $607 \pm 16$ \\
\hline $\begin{array}{l}\text { Rapeseed oil, } \\
\text { cold-pressed } 2\end{array}$ & $153 \pm 6$ & nd & nd & $469 \pm 14$ & nd & $\operatorname{tr}$ & $622 \pm 20$ \\
\hline $\begin{array}{l}\text { Rapeseed oil, } \\
\text { cold-pressed } 3\end{array}$ & $239 \pm 6$ & nd & nd & $474 \pm 12$ & nd & $\operatorname{tr}$ & $713 \pm 18$ \\
\hline $\begin{array}{l}\text { Rapeseed oil, } \\
\text { cold-pressed } 4\end{array}$ & $213 \pm 2$ & nd & nd & $433 \pm 3$ & nd & $\operatorname{tr}$ & $646 \pm 5$ \\
\hline $\begin{array}{l}\text { Rapeseed oil, } \\
\text { cold-pressed } 5\end{array}$ & $181 \pm 6$ & nd & nd & $460 \pm 5$ & nd & $\operatorname{tr}$ & $641 \pm 11$ \\
\hline $\begin{array}{l}\text { Rapeseed oil, } \\
\text { cold-pressed } \\
\text { (organic) }\end{array}$ & $245 \pm 3$ & nd & nd & $399 \pm 13$ & nd & $\operatorname{tr}$ & $644 \pm 16$ \\
\hline $\begin{array}{l}\text { Rapeseed oil, } \\
\text { warm-pressed }\end{array}$ & $255 \pm 3$ & nd & nd & $467 \pm 8$ & nd & tr & $722 \pm 11$ \\
\hline $\begin{array}{l}\text { Rapeseed oil } \\
\text { (fully refined) }\end{array}$ & $256 \pm 4$ & nd & nd & $433 \pm 9$ & nd & $\operatorname{tr}$ & $689 \pm 13$ \\
\hline
\end{tabular}

SD, standard deviation; tr, detected in amounts $<0.5 \mu \mathrm{g} / \mathrm{g}$ oil; nd, not detected.

Crews et al. (2005) observed $\alpha$-Tp in different varieties of hazelnut oil varying in the range of 314$548 \mu \mathrm{g} / \mathrm{g}$ except for one Italian variety which had $118 \mu \mathrm{g} / \mathrm{g}$. A lower level, such as $94 \mu \mathrm{g} / \mathrm{g}$, has been reported by Parcerisa et al. (1998) and it was comparable to the $87 \mu \mathrm{g} / \mathrm{g}$ observed in our study.

The level of $\gamma$-Tp in the rapeseed oil samples was generally higher (396 $-474 \mu \mathrm{g} / \mathrm{g}$ oil) compared with other oils except for argan and sesame oil samples which contained 463 and $521 \mu \mathrm{g} / \mathrm{g}$ oil, respectively. The highest level of $\alpha$-Tp was observed in fully refined and warm pressed rapeseed oil samples followed by the organic cold pressed rapeseed oil sample. The high total Tp observed in the warm pressed sample may suggest better extraction of the tocopherols from the structural components of seeds (Falk and Munné-Bosch, 2010). Alpha and $\gamma$-Tp in rapeseed oil samples were comparable with the published data (Koski et al., 2002, Schwartz et al., 2008). In the latter study, it was shown that organic rapeseed oil had a generally lower content of $\alpha$-Tp but slightly higher level of $\gamma$-Tp, compared with refined and cold pressed rapeseed oils.

\subsection{Sterol content}

The content and composition of sterols in different specialty oil samples are presented in Table 3. The total sterol content of the oil samples varied in a range between 889-6204 $\mu \mathrm{g} / \mathrm{g}$ oil, except for the rice bran oil. The predominant sterol was $\beta$-sitosterol followed by other common desmethyl sterols such as campe-, stigma- and $\Delta 5$-avenasterol in all the samples except in argan oil. Individual as well as total sterol contents in hazelnut oil were in good agreement with the published data (Crews et al., 2005). A rather similar sterol profile was found in the avocado oil sample but the total sterol content was twice the amount observed in nut oils.

Argan oil showed a characteristically different sterol profile compared to all the other oil samples. The major sterols identified were schottenol which represents $51 \%$ and spinasterol with $46 \%$ of the total identified sterols. The observed sterol profile of argan oil was comparable with the data published by Khallouki et al. (2003). However, the content of each type of sterol observed in our study was much 


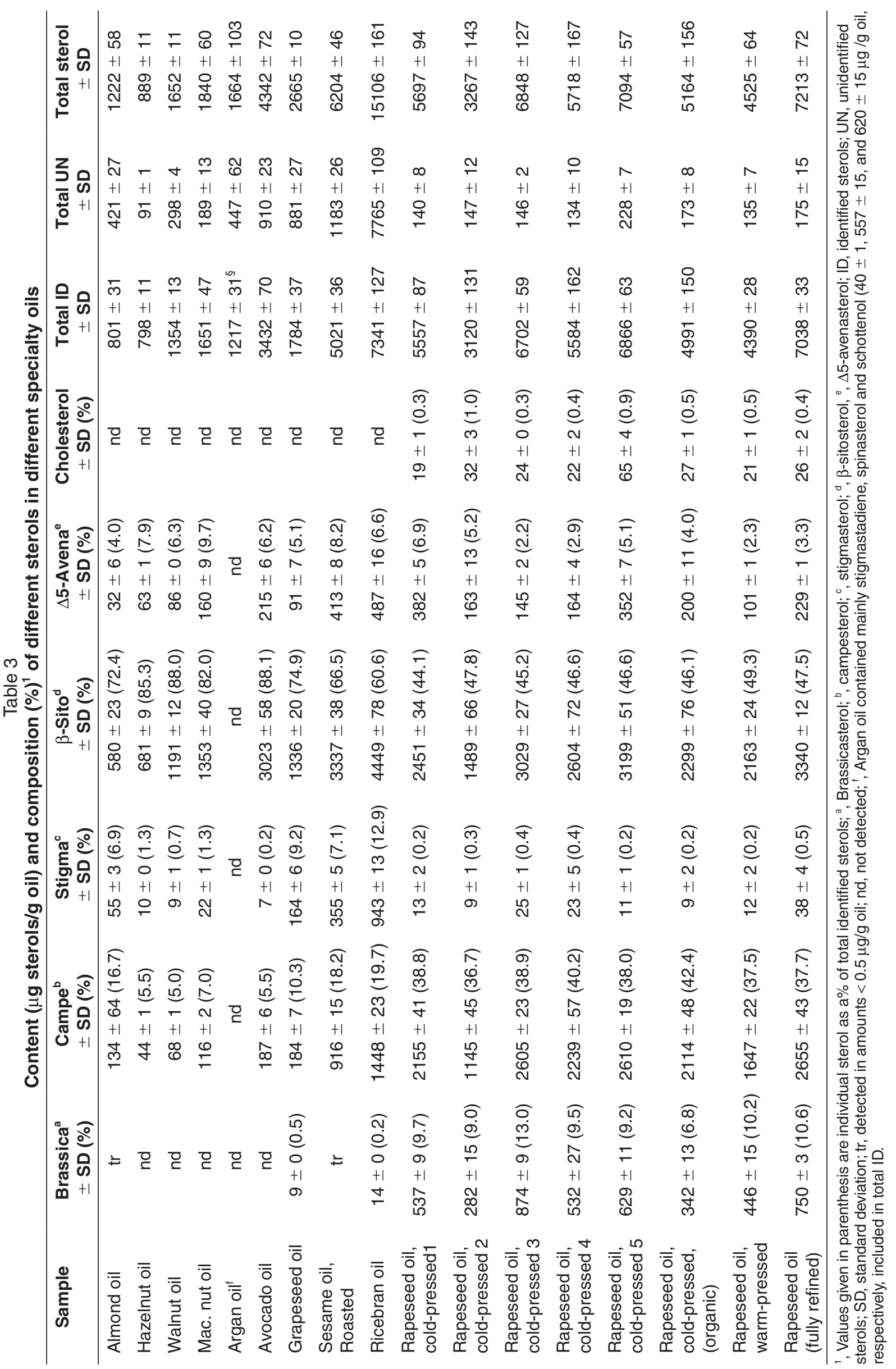


lower than their values. The total sterol content of grape seed oil was in agreement with the Codex range (1999) and for Italian varieties (Crews et al., 2006). Though the origin of the grape seed oil in our study is not known, the relative proportion of the individual sterols identified as $\%$ total identified were similar to the Italian varieties rather than the French and Spanish varieties analyzed in their study.

The individual and total sterol contents observed in our study for roasted sesame oil were in the range mentioned by Crews et al. (2006). Rice bran oil contained the highest amount of sterols in this study, which concurs with the published literature (Kochhar, 2002, Piironen et al., 2000). In addition to the highest total sterol levels, a considerably high level of stigmasterol $(13 \%)$ was observed in the rice bran oil sample compared with the other oil samples analyzed.

The content of sitosterol greatly varied from $1489-3340 \mu \mathrm{g} / \mathrm{g}$ in the rapeseed oil samples. Sitosterol was the predominant sterol (44-49\%) but as an individual sterol, sitosterol was lower when compared with the other specialty oil or nut oil samples analyzed in this study (Table 3 ). The lower proportion of sitosterol was compensated by a higher percentage of campesterol. The brassicasterol content varied from $282-874 \mu \mathrm{g} / \mathrm{g}$ while it was 1145 $2655 \mu \mathrm{g} / \mathrm{g}$ for campesterol, and $\Delta 5$-avenasterol was present in moderate levels. Despite the variation in individual sterol contents among the different rapeseed oil samples, their relative proportions remained uniform. The content of different sterols observed were in line with previously published data
(Schauss, 2008; Schwartz et al., 2008). The authors observed no clear relationship regarding their origin such as organic rapeseed oil or the processing method. However, the relative proportion of brassicasterol in organic rapeseed oil sample $(7 \%)$ was considerably lower compared to other rapeseed oil samples. The authors also confirmed that sterol contents were roughly the same in crude and refined rapeseed oil or cold pressed organic rapeseed oils.

Variations in individual and total sterol contents in the oil can be due to genetic factors among varieties, growing and storage conditions, refining, etc., but the relative percentage composition of individual sterols generally remains similar. Some plant sterols are partly removed during industrial oil refining depending on the extent of refining conditions (Piironen et al., 2000). In our study, the lowest level of $\Delta 5$-avenasterol $(101 \mu \mathrm{g} / \mathrm{g}$ oil) was observed in the warm pressed rapeseed oil sample compared with the other rapeseed oil samples and ranged from $145-382 \mu \mathrm{g} / \mathrm{g}$ oil. In addition, the lowest total sterol content was observed in the warm pressed rape seed oil sample, with the exception of one sample (cold pressed 2 rapeseed oil).

\subsection{Oxidative stability}

The results of the oxidative stability tests for specialty oils are given in Table 4 . The peroxide value $(\mathrm{PV})$ of the different oils was in the range of $0.5-1.3 \mathrm{meq} \mathrm{O}_{2} / \mathrm{kg}$ oil, indicating freshly produced oils with their characteristic flavors. Peroxides are

Table 4

Oxidative status parameters of different specialty oils

\begin{tabular}{|c|c|c|c|c|}
\hline Sample & $P^{a}( \pm S D)$ & $A V^{b}( \pm S D)$ & $T V^{c}( \pm S D)$ & Rancimat $^{c}$ \\
\hline Almond oil & $1.1 \pm 0.1$ & $12.6 \pm 0.3$ & $14.8 \pm 0.2$ & 10.2 \\
\hline Hazelnut oil & $1.1 \pm 0.0$ & $7.5 \pm 0.0$ & $9.7 \pm 0.1$ & 16.0 \\
\hline Walnut oil & $0.9 \pm 0.0$ & $3.9 \pm 0.1$ & $5.7 \pm 0.1$ & 4.2 \\
\hline Macadamia nut oil & $0.5 \pm 0.0$ & $0.8 \pm 0.0$ & $1.8 \pm 0.0$ & 37.0 \\
\hline Argan oil & $1.1 \pm 0.0$ & $1.0 \pm 0.0$ & $3.2 \pm 0.1$ & 27.6 \\
\hline Avocado oil & $1.2 \pm 0.1$ & $1.2 \pm 0.1$ & $3.6 \pm 0.3$ & 16.9 \\
\hline Grapeseed oil & $1.0 \pm 0.0$ & $15.5 \pm 0.1$ & $17.5 \pm 0.1$ & 8.9 \\
\hline Sesame oil (roasted) & $0.6 \pm 0.0$ & $10.9 \pm 0.1$ & $12.1 \pm 0.1$ & 18.0 \\
\hline Rice bran oil & $1.1 \pm 0.1$ & $4.2 \pm 0.0$ & $6.4 \pm 0.1$ & 18.7 \\
\hline Rapeseed oil, cold-pressed 1 & $1.0 \pm 0.0$ & $1.2 \pm 0.1$ & $3.2 \pm 0.1$ & \\
\hline Rapeseed oil, cold-pressed 2 & $1.1 \pm 0.0$ & $1.6 \pm 0.0$ & $3.8 \pm 0.1$ & \\
\hline Rapeseed oil, cold-pressed 3 & $1.3 \pm 0.1$ & $0.5 \pm 0.0$ & $3.1 \pm 0.2$ & \\
\hline Rapeseed oil, cold-pressed 4 & $1.1 \pm 0.0$ & $0.7 \pm 0.1$ & $2.9 \pm 0.1$ & \\
\hline Rapeseed oil, cold-pressed 5 & $1.0 \pm 0.0$ & $2.1 \pm 0.1$ & $4.1 \pm 0.1$ & \\
\hline Rapeseed oil, cold-pressed (organic) & $1.1 \pm 0.0$ & $1.2 \pm 0.1$ & $3.4 \pm 0.1$ & \\
\hline Rapeseed oil, warm-pressed & $1.2 \pm 0.0$ & $1.8 \pm 0.0$ & $4.2 \pm 0.1$ & \\
\hline Rapeseed oil (fully refined) & $1.1 \pm 0.1$ & $1.7 \pm 0.1$ & $3.9 \pm 0.1$ & \\
\hline
\end{tabular}

${ }^{\mathrm{a}} \mathrm{PV}$, Peroxide value $\left(\mathrm{mEq} \mathrm{O}_{2} / \mathrm{kg}\right.$ oil); ${ }^{\mathrm{b}} \mathrm{AV}$, Anisidine value; ${ }^{\mathrm{c}} \mathrm{TV}$,Totox value $=2$ (Peroxide value) + (Anisidine value); ${ }^{\mathrm{d}}$, Rancimat value (hours) at $100^{\circ} \mathrm{C} ; \mathrm{SD}$, standard deviation. 
formed during early/initial stages of oil oxidation, and the PV was very low in all the oil samples, compared with the values of the Codex standard for vegetable oils (1999). Secondary oxidation products in the oils such as high molecular weight saturated and unsaturated carbonyl compounds were measured as anisidine value (AV), and were in the range of 0.5-15.5 for all the analyzed samples. The totox value (TV), a measurement of the total oxidation status of oil, was calculated as $2 \times$ PV + AV and ranged from 1.9-17.5. Secondary oxidation products, measured as AV and TV, were considerably higher in the oil samples from grape seed, almond and roasted sesame. However, underlying reasons could not be explained from the lipid composition without accurate background information on the samples. There were no remarkable differences in the lipid oxidation parameters tested for different rapeseed oil samples. The PV values in differently processed rapeseed oils were considerably lower than previously published results from cold pressed rapeseed samples in Finland (Pekkarinen et al., 1998; Koski et al., 2002).

Rancimat induction time at $100^{\circ} \mathrm{C}$ varied from 4.2-37 hours in the specialty oil samples, except for the rapeseed oils. Among the oils tested, walnut oil was the least heat stable oil. On the other hand, macadamia nut oil was the most stable oil followed by argan, rice bran and roasted sesame oil. The relatively high stability of rice bran oil is most likely due to the combined effect of oryzanol, phytosterols, squalene, tocopherols and tocotrienols; while the stability of roasted sesame oil is due to the high antioxidant activity of sesamol formed from sesamolin during roasting and the high level of the potent antioxidant $\gamma$-tocopherol (Kochhar, 2002).

According to Savage et al. (1999), who did a study on walnut oil, Rancimat value had a negative correlation with 18:2, 20:1, and 18:1n-9 contents but 18:3 did not show a strong relationship with Rancimat value. Similarly, macadamia nut oil, which contained only 3.7\% PUFA, showed high oxidative stability despite low levels of tocopherols and tocotrienols. This can be a reason for the comparatively lower Rancimat value of walnut oil than grape seed oil even though they had close levels of total PUFA, MUFA and SFA. Miraliakbari and Shahidi (2008) also noted walnut oil as the least stable and most unsaturated while almond and hazelnut exhibited intermediate stability in a study on the oxidative stability of tree nut oils. Also, grape seed oil contained $216 \mu \mathrm{g} / \mathrm{g} \alpha$-tocopherol compared to walnut oil which contained only $71 \mu \mathrm{g} / \mathrm{g}$ oil.

Rice bran and argan oil showed comparable fatty acid profiles although argan oil showed a comparatively higher stability against heat induced oxidation. On the other hand, argan, rice bran and toasted sesame oil, which had moderate levels of PUFA (33-44\%) and MUFA (42-45\%), showed comparatively higher Rancimat values. It appears that the association of high levels of tocopherols (especially $\gamma$ - and $\delta$-, above $400 \mu \mathrm{g}$ ) with some unknown minor potent components might contribute significantly towards the high oxidative stability of argan oil, which warrants further investigation.

\section{CONCLUSIONS}

This paper adds to and updates the available compositional data for several commercially available specialty oils along with some cold pressed and organic cold pressed rapeseed oils. It seems that the oxidative stability of many specialty oils tested in our study was affected mainly by their fatty acid profiles and tocopherol and tocotrienol contents of the oil. The different specialty oils tested showed unique profiles and vary among each other in fatty acid, tocol and sterol profiles. Macadamia nut oil was found to be the most stable oil followed by argan oil: while walnut oil was the least stable among all the oils examined. It is thought that the high oxidative stability of argan oil is probably due to the combined effect of potent tocopherols ( $\gamma$ - and $\delta$-) and other potent antioxidative components. Rapeseed oil represents one of the major oils which is naturally rich in tocopherols and sterols with a unique fatty acid composition (with good ratio of $\omega-6$ and $\omega-3$ fatty acid, $2: 1)$. There were no clear differences among the different commercially available brands of cold pressed, organically produced cold pressed, warm pressed or refined (general purpose) rapeseed oils.

\section{ACKNOWLEDGEMENTS}

We would like to thank Dr. Kumari Ubhayasekera at Food Chemistry Lab, SLU, for technical support during laboratory analysis.

\section{REFERENCES}

AbidiS L. 2003. Tocol derived minor components in selected plant seed oils. J. Am. Oil Chem. Soc. 80, 327-333.

Azadmard-Damirchi S, Dutta P C. 2008. Stability of minor lipid components with emphasis on phytosterols during chemical interesterification of a blend of refined olive oil and palm stearin. J. Am. Oil Chem. Soc. 85, 13-21.

Charrouf Z, Guillaume D. 2008. Argan oil: Occurrence, composition and impact on human health. Eu. J. Lipid Sci. Technol. 110, 632-636.

Codex Alimentarius. 2001.Codex standard for named vegetable oils (CODEX-STAN 210-1999), 8, 11-25.

Crews C, Hough P, Godward J, BreretonP, Lees M, Guiet S, Winkelmann W. 2005. Study of the main constituents of some authentic hazelnut oils. J. Agric. Food Chem. 53, 4843-4852.

Crews C, Hough P, Godward J, Brereton P, Lees M, Guiet S, Winkelmann W. 2005. Study of the main constituents of some authentic walnut oils. J. Agric. Food Chem. 53, 4853-4860.

Crews C, Hough P, Brereton P, Godward J, Lees M, Guiet S, Winkelmann W. 2006. Quantitation of the main constituents of some authentic sesame seed oils of different origin. J. Agric. Food Chem. 54, 6266-6270. 
Dubois V, Breton S, LinderM, Fanni J, Parmentier M. 2007. Fatty acid profiles of 80 vegetable oils with regard to their nutritional potential. Eur J. Lipid Sci. Technol. 109, 710-732.

EscurriolV, Cofan M, Serra M, Bullo M, Basora J, SalasSalvado J, Corella D, Zazpe I, Martinez-Gonzalez M A, Ruiz-Gutierrez V, Estruch R, Ros E.2009. Serum sterol responses to increasing plant sterol intake from natural foods in the Mediterranean diet. Eu. J. Nutr. 48, 373-382.

Falk J, Munné-Bosch S. 2010. Tocochromanol functions in plants: antioxidation and beyond. J. Exp. Bot. 61, 1549-1566.

Franke AA, Murphy SP, Lacey R, Custer LJ. 2007. Tocopherol and tocotrienollevels of foods consumed in Hawaii. J. Agric. Food Chem. 55, 769-778.

Gutierrez F, Arnaud T, Albi M A. 1999. Influence of ecological cultivation on virgin olive oil quality. J. Am. Oil Chem. Soc. 76, 617-621.

Determination of peroxide value: Anhydrous milk fat.IDF Standard7A. 1991. International Dairy Federation. Brussels, Belgium.

Determination of the p-Anisidine Value, Method 2.504. 1987. IUPAC standard methods for the analysis of oils, fats and derivatives (7th ed.), Oxford: Alden Press, Oxford, pp. 210-211.

Jung S, Maurer D, Johnsson L A. 2009. Factors affecting emulsion stability and quality of oil recovered from enzyme-assisted aqueous extraction of soybeans. Biores. Technol. 100, 5340-5347.

Kaijser A, Dutta P, Savage G. 2000. Oxidative stability and lipid composition of macadamia nuts grown in New Zealand. Food Chem. 71, 67-70.

Khallouki F, Younos C, Soulimani R, Oster T, Charrouf Z, Spiegelhalder B, Bartsch H, Owen R W. 2003. Consumption of argan oil (Morocco) with its unique profile of fatty acids, tocopherols, squalene, sterols and phenolic compounds should confer valuable cancer chemopreventive effects. Eur. J. Canc. Prev. 12, 67-75.

Kochhar S P. 2002. Sesame, rice-bran and flaxseed oils. In:GunstoneF. D. (Ed.), Vegetable oils in food technology, Blackwell Publishing Ltd., Oxford, pp. 297-326.

Koski A, Psoimiadou E, Tsimidou M, Hopia H, Kefalas P, Wähälä K, Heinonen M. 2002. Oxidative stability of virgin olive oil and cold pressed rapeseed oil. Eur. Food Res. Technol. 214, 214-298.

Lairon D. 2010. Nutritional quality and safety of organic food. A review. Agron. Sust. Dev. 30,33-41.

Lu Q-Y, Zhang, Y, Wang Y, Wang D, Lee R-P, Gao K, Byrns R, Heber D. 2009. California Hass avocado: Profiling of carotenoids, tocopherol, fatty acid, and fat content during maturation and from different growing areas. J. Agric. Food Chem. 57, 10408-10413.

Maguire L S, O'Sullivan S M, Galvin K, O'Connor T P, O'Brien N M. 2004. Fatty acid profile, tocopherol, squalene and phytosterol content of walnuts, almonds, peanuts, hazelnuts and macadamia nut.Int. J. Food Sci. Nutr. 55, 171-178.

Miraliakbari H, Shahidi F. 2008. Oxidative Stability of tree Nut Oils. J. Agric. Food Chem. 56, 4751-4759.

Normén L, Frohlich J, Trautwein E. 2004. Role of plant sterols in cholesterol lowering. In: Dutta P C. (Ed.), Phytosterols as functional food components and nutraceuticals, Marcel Dekker, Inc.New York, pp. 243-315.

Parcerisa J, Richardson D G, Rafecas M, Codony R, Boatella J. 1998. Fatty acid, tocopherol and sterol content of some hazelnut varieties (Coryllus avellana L.) harvested in Oregon (USA). J. Chromatog. A. 805, 259-268.

Pekkarinen S, Hopia A, Heinonen M. 1998. Effect of processing on the oxidative stability of low erucic acid turnip rapeseed (Brassica rapa) oil. Fett/Lipid. 100, 69-74.

Piironen V, Lindsey DG, Miettinen TA, Toivo J, Lampi AM. 2000. Plant sterols: biosynthesis, biological function and their importance to human nutrition. A review, J. Sci. Food Agric. 80, 939-966.

Rubio M, Alvarez-Ortí M, Alvaruiz A, Fernández., Pardo J E. 2009. Characterization of oil obtained from grape seeds collected during berry development. J. Agric. Food Chem. 57, 2812-2815.

Savage GP, McNeil DL, Dutta P C. 1997.Lipid composition and oxidative stability of oils in hazelnuts (Corylusavellana L.) grown in New Zealand. J. Am. Oil Chem. Soc. 74, 755-759.

Savage G P, Dutta P C, McNeil D L. 1999. Fatty acid and tocopherolcontents and oxidative stability of walnut oils. J. Am. Oil Chem. Soc.76, 1059-1063.

Schauss A G. 2008.Tocotrienols: A review. In: Watson $R$ R, Preedy V R. (Eds.), Tocotrienols: Vitamin E beyond tocopherols, CRC Press, Boca Raton. pp. 3-12.

Schwartz H, Ollilainen V, Piironen V, Lampi A-M. 2008. Tocopherol, tocotrienol and plant sterol contents of vegetable oils and industrial fats. J. Food Compos. Anal. 21, 152-161.

Tasan M, Gecgel U, Demirci M. 2011. Comparison of geometrical isomerization of unsaturated fatty acids in selected commercially refined oils. Grasas y Aceites. 62, 284-289

Recibido: $18 / 8 / 11$ Aceptado: 4/10/11 